work on natural selection that enables him to repeat the old cliché. What he calls the underlying logic of evolutionary theory "seems to say no more than that survivors survive". This hoary fallacy has been refuted many times, but he does not say so.

Mr Brent must surely have a considerable readership; his abilities in his own line are outstanding. The present book should be asked for as "the latest Peter Brent", rather than as a successful study of Darwin. No scientist need bother with it. [?]

A.J. Cain is Derby Professor of Zoology in the University of Liverpool.

\section{Rare air of motion}

\section{R. Hide}

Dynamics of the Upper Atmosphere. By Susumo Kato. Pp.233. ISBN 90-277-1132-1. (Reidel: 1980.) Dfl. 57, \$29.95.

TECHNIQUES for investigating high-level atmospheric motions have advanced considerably over the past 20 years, with the introduction of rockets, satellites and high-powered radar on the observational side, and the advent of computers for the analysis of data and their theoretical interpretation in terms of basic physical processes.

Professor Sato's monograph - the first in a series, Developments in Earth and Planetary Sciences, stressing Japanese work but written in English - is a mathematically orientated introduction to the study of these motions and it reflects not only the author's main research interests but also (I imagine) his activities as a teacher of applied mathematics. The book deals in a straightforward and fairly standard way with the basic equations of dynamics, thermodynamics and electrodynamics applied to the atmosphere. These equations are used to describe the main properties of acoustic gravity waves and atmospheric tides and their manifestation in observations of the ionosphere. The presentation is strongly slanted towards those who are primarily interested in mathematical aspects of atmospheric wave propagation but many observational data are given in this profusely illustrated book, with its 106 diagrams and many tables.

Most atmospheric physicists would find something useful in the book, but it is possibly too narrow and, in parts, too detailed to be useful as an introductory text. The standard of English leaves much to be desired in places but this can hardly be blamed on the author, who should have been better served by his publisher.

$R$. Hide is at the Geophysical Fluid Dynamics Laboratory of the Meteorological Office, Bracknell, Berkshire.

\title{
News from the petroleum geologists
}

\section{J.R.V. Brooks}

Petroleum Geology of the Continental Shelf of North-West Europe, 1981. Edited by L.V. Illing and G.D. Hobson. Pp.521. ISBN 0-85501-656-6. (Heyden \& Son: 1981.) £47, \$113.

IT IS now some 16 years since the first discovery of offshore gas in UK waters, and 13 years since the first commercial discovery of oil. In the period from 1964 to the present nearly 1,800 wells have been drilled.

To those involved in exploration and in the production of oil and gas these have been, and still are, exciting times filled with geological surprises. But to many geologists - nearly a generation of them the scientific results of drilling have not been easily available, and it is increasingly apparent that universities - let alone schools - do not have the finances to purchase the data that now exist. Study of the geology of the UK and continental landmass of Western Europe gives only a partial picture of the total geology and geological history of the area. But when this is linked to what is now known about the North Sea Basins and other offshore areas, a more complete and meaningful picture emerges. From a teaching point of view, and to large numbers of geologists in non-oil areas, it is important that this new information becomes incorporated into the present state of knowledge.

Up-to-date data are hard to come by, but from time to time the industry holds a conference during which current views are aired and papers on exploration and proven fields published. The first conference on the petroleum geology of the continental shelf of North-West Europe was held in 1974, and the second in 1980 in London; it is the proceedings of the 1980 meeting which form the contents of the volume reviewed here.

The number (46) and range of papers presented is great; they are grouped into four main categories covering regional aspects of geology, technological developments, stratigraphy, and selected oil and gas fields. In some cases the opportunity has been taken to update material presented at the 1974 conference, but the majority of papers record more recent and current work, and present previously unpublished data.

Certain contributions were specially commissioned by the conference committee, notably those on temperature and thermal gradients in the North Sea, the regional seismic maps of the North Sea, and the subcrop map of the mid Mesozoic unconformity, the latter providing a particularly useful overview.

Clearly one cannot mention every single contribution and all of them are worthy of study, but there are a number of more significant papers that represent milestones in exploration activity. Of these, the Brae field is as near as we have come to finding a stratigraphic accumulation of oil and its discovery has led to a search for further accumulations of this type. The discovery of the Frigg field is perhaps a unique example of a sedimentary unit which can be readily identified on a seismic section and might be described as a seismic/structural accumulation. In fact it is described as a preserved deep sea fan.

The largest discovery of oil onshore, made in 1973 at Wytch Farm, set off renewed interest in landward hydrocarbon exploration, which is currently being sustained. The results of this discovery have had considerable geological implications for exploration elsewhere in the UK, and the paper on Wytch Farm sets out the results and regional setting of the discovery.

Each of the papers in the volume represents recent results of exploration activity and might be considered as highlights of the book, published as they are for the first time. But the regional and field evaluations also serve to give the technical reader a wide overview of current hydrocarbon activity.

Such is the vast range and wealth of geology presented in this volume that no geologist, particularly those whose task it is to teach the subject, should be without a copy. Sadly, however, its cost may preclude the sort of distribution its contents deserve.

J.R.V. Brooks is Head of the Geology and Geophysics Branch of the Petroleum Engineering Division, Department of Energy, London.

\section{Greater clarity in lens biology}

\section{Christine Slingsby}

Molecular and Cellular Biology of the Eye

Lens. Edited by Hans Bloemendal. Pp.469. ISBN 0-471-05171-3. (Wiley: 1981.) £50.65, $\$ 91.15$.

PROGRESS in eye lens research, whilst resulting in a greater understanding of the organelle itself and its diseases, may also lead to discoveries in areas of more general interest. In his selection of ten contributions for this book, Professor Bloemendal has placed emphasis on the growing interest in cytoskeletal structures, as the role they play in controlling and maintaining cell shapes can be well observed in lens cells. To this end, the chapter by Lucio Benedetti et al. is 